\title{
A 17 year experience of attrition from care among HIV infected children in Nnewi South-East Nigeria
}

\author{
Chinyere Ukamaka Onubogu ${ }^{1,2^{*}}$ and Ebelechuku Francesca Ugochukwu ${ }^{1,2}$
}

\begin{abstract}
Background: A large number of HIV-infected children continue to die despite reported scale-up of paediatric HIV services.

Aim: The trend in attrition among children enrolled in an anti-retroviral therapy (ART) programme was evaluated.

Methods: This was a retrospective review of children enrolled into NAUTH ART programme between 2003 and 2019.

Results: 1114 children < 15 years at enrolment were studied. The male: female ratio was 1:1 while median age at enrolment was 4.3 years. About two-thirds had WHO stage 3 or 4 disease at enrolment. The rate of loss to followup (LTFU) and death were 41.0 and 8.4\%, respectively, with overall attrition incidence of 108/1000PY. Despite the downward trend, spikes occurred among those enrolled in 2008 to 2011 and in 2017. The trend in 6-, 12-, 24- and 36 -months attrition varied similarly with overall rates being 20.4, 27.7, 34.3 and $37.3 \%$, respectively. Among those on ART, $>50 \%$ of attrition was recorded within 6 months of care. Advanced WHO stage, young age, non-initiation on ART or period of enrolment $(P<0.001)$, and caregiver $(p=0.026)$ were associated with attrition in bivariate analysis. Apart from caregiver category, these factors remained significant in multivariate analysis. Most LTFU could not be reached on phone. Among those contacted, common reasons for being lost to follow-up were financial constraints, caregiver loss, claim to divine healing, family disharmony/child custody issues and relocation of family/child.

Conclusion/recommendation: Attrition rate was high and was mostly due to LTFU. Predictors of attrition were late presentation, young age, delay in ART initiation and financial constraints. Efforts should be intensified at early diagnosis, linkage to care and implementation of "test and treat" strategy. Innovative child centered approaches should be adopted to enable the HIV-infected children remain in care despite challenges which can truncate treatment.
\end{abstract}

Keywords: Childhood HIV, Retention in care, Death, Loss to follow-up, Sub-Saharan Africa

\footnotetext{
* Correspondence: cu.onubogu@unizik.edu.ng

'Department of Paediatrics, Faculty of Medicine, Nnamdi Azikiwe University, Awka, Nigeria

${ }^{2}$ Paediatric Infectious Diseases Unit, Nnamdi Azikiwe University Teaching

Hospital, Nnewi, Nigeria
}

(c) The Author(s). 2021 Open Access This article is licensed under a Creative Commons Attribution 4.0 International License, which permits use, sharing, adaptation, distribution and reproduction in any medium or format, as long as you give appropriate credit to the original author(s) and the source, provide a link to the Creative Commons licence, and indicate if changes were made. The images or other third party material in this article are included in the article's Creative Commons licence, unless indicated otherwise in a credit line to the material. If material is not included in the article's Creative Commons licence and your intended use is not permitted by statutory regulation or exceeds the permitted use, you will need to obtain permission directly from the copyright holder. To view a copy of this licence, visit http://creativecommons.org/licenses/by/4.0/ The Creative Commons Public Domain Dedication waiver (http://creativecommons.org/publicdomain/zero/1.0/) applies to the data made available in this article, unless otherwise stated in a credit line to the data. 


\section{Introduction}

Infection with the human immunodeficiency virus (HIV) still presents a serious public health concern particularly among children. Despite efforts to improve services and outcomes of children living with HIV, a large number of children continue to die from HIV annually $[1,2]$. , Although children less than 15 years old constituted 4.5\% of all individuals living with HIV in 2018, they accounted for $13 \%$ of the 770,000 deaths attributable to HIV [2]. In 2018, the incidence of HIV-related mortality in children tripled that of adults (5.9\% versus $1.9 \%$ ) [2].

More than $90 \%$ of HIV infection in children result from mother-to-child transmission (MTCT) during pregnancy, delivery or postnatally during breastfeeding [3]. Such perinatally acquired HIV is associated with more rapid progression due to immature immune system, and high mortality especially in sub-Saharan Africa [3]. Without any intervention, $50 \%$ of prenatally infected children die within their first two years of life. Fortunately, anti-retroviral therapy (ART) has enabled many children to grow into adulthood [3, 4]. However, the success of childhood HIV programmes depends on timely diagnosis, early initiation of treatment, adherence to medications and active follow-up, to ensure optimal outcomes. This is hinged on frequent visits to treatment sites for clinic consultations, laboratory monitoring and ARV drug refill. Due to changing life circumstances, care giver issues and other challenges, many children in developing countries may not meet up with the demands of life-long care and therefore unable to continue enjoying the life-saving benefits of ART. Consequently, the children are faced with high risk of treatment failure, death and HIV transmission [5].

In 2014, the Joint United Nations Programme on HIV/ AIDS (UNAIDS) and partners set ambitious 90-90-90 fast-track targets, that $90 \%$ of people living with HIV know their status, $90 \%$ of people who know their status be on treatment, and $90 \%$ of people on treatment be virally suppressed by 2020 [6]. In order to end the AIDS epidemic, these targets were set at 95-95-95 by year 2030 [7]. However, these targets cannot be met if children fail to be retained in care. Children continue to lag behind adults across all cascades, and reports indicate that all paediatric targets set for 2016 were missed $[1,7]$. Despite reported scale-up of testing and enrolment services, only about half of HIV-infected children less than 15 years were receiving ART in 2019 [7]. Besides, the confinement measures, restrictions on movement and economic stresses brought by the Covid-19 pandemic may consequentially cause disruption of services and treatment interruptions.

This study was carried out as a consequence, to determine the trend in attrition among children enrolled into the paediatric ART programme in Nnamdi Azikiwe
University Teaching Hospital (NAUTH) Nnewi, Nigeria. It is hoped that the findings will provide the needed evidence to drive the adoption of innovative approaches which will ensure retention in care and optimal outcomes among HIV-infected children.

\section{Subjects and methods \\ Study site}

The study was conducted in NAUTH, Nnewi, Anambra State, Nigeria. The hospital offers tertiary services to the entire Anambra State and neighboring south-east Nigerian states. The paediatric ART programme formally started in the site in 2003. The NAUTH Paediatric HIV Unit is manned by adequately trained staff. Clinic consultations hold every working day (Mondays through Fridays) while in-patient services are offered on a daily basis.

Initiation of children on ART was based on Nigerian National HIV treatment guidelines which are in line with the World Health Organization (WHO) recommendations [8-11]. Prior to 2016, children were initiated on ART using eligibility criteria which included WHO clinical stage, immunologic (CD4 cell count) status and age of the child. However, Nigeria adopted the "test and treat" approach, in 2016, which recommended that ART should be initiated in all individuals with a diagnosis of HIV, regardless of WHO clinical stage and CD4+ cell count, within two weeks of diagnosis [11]. In addition to ART, the children were routinely screened for opportunistic or co-infections such as Tuberculosis, Pneumocystis jirovecci pneumonia, Hepatitis $\mathrm{B}$ and $\mathrm{C}$ among other infections. They also received prophylaxis for the opportunistic infections or treatments where necessary. All treatments were monitored clinically, and with laboratory investigations.

Generally, children on ART were seen at two-weeks after ART initiation, then monthly for three months. Thereafter, they were seen two-monthly, except when unstable. During the pre-ART era, visits for the children in the pre-ART pool was three monthly or less depending on their clinical condition. The children were routinely tracked to ensure continued engagement in care using standard guidelines, and procedures. HIV clinic appointments were scheduled in appointment registers. Children who missed scheduled appointments were daily identified and subsequently tracked through phone calls to their parents or caregivers.

\section{Methods}

The records of all children enrolled into NAUTH paediatric ART programme over a 17 year period (1st January 2003 to 31st December 2019) was reviewed to document the trend in attrition Data of the children were prospectively recorded in the ART treatment registers domiciled 
in the clinic and on an electronic platform. This included their date of birth, date of enrolment, age and clinical parameters at enrolment, address, sex, and phone contact and caregiver details. On every clinic visit, the record was updated to reflect dates of subsequent visits, anti-retroviral drugs (ARV) status and regimen, as well as and the next appointment date. The date of cessation of care in the unit was also recorded together with final outcomes such as transfer to other sites, transition to adult ART programme, death or loss to follow-up. These data were abstracted using a proforma between 1st and 31st July 2020 .

Using the phone numbers provided, caregivers of those who were lost to follow-up were contacted to determine further outcomes such as death, alive and receiving care elsewhere or alive but not in any form of care. Those who were alive but not in any form of care were encouraged to return to care. Details of all children who were alive but not in care and those who could not be reached were handed over to the Home Based Tracking Unit (HBTU) for further tracking and possible home visit.

\section{Data analysis}

Data was analyzed using SPSS version 22. The primary outcomes were retention in care (still in Paediatric ART care, transitioned to adult ART or transferred out to another facility) or attrition (documented death or lost to follow-up). For the purpose of this study, loss to follow-up was defined as failure to return to care for $\geq 6$ months after a scheduled clinic appointment. Retention in paediatric ART care was defined as being alive and receiving care from the unit, or documented transition to adult ART program or transfer to another site offering paediatric ART services. Death was defined as documented death within the period of care either while on admission in the facility or prior to a scheduled follow-up visit.

The duration of care or time to event was determined by subtracting the date of enrolment from the date of censoring. Those dead, lost to follow-up or transferred were censored on the date of their last hospital visit while those in care were censored on the final date of data abstraction (31st July 2020). The attrition rate per 1000 person years was calculated (using the formula attrition/1000PY $=$ [number of attrition/cumulative person time years] $\times 1000$ ) for the entire population as well as different categories.

The characteristics of children who were retained in care, dead or lost to follow-up were described using frequency tables for categorical variables while the continuous variables were described using median and interquartile range (IQR) or mean and standard deviation where applicable. The difference in these characteristics were compared using Pearson's Chi-square test for categorical variables, Kruskal Wallis test for non-normally distributed continuous variables and one-way ANOVA for normally distributed continuous variables. Kaplan Meier curves with log rank tests were used to describe and compare attrition according to use of ARVs or not. Outcomes, overall attrition rate, and 6-, 12-, 24- and 36-months attrition rates were represented in charts according to year of enrolment. Cox regression analysis was used to examine the association between attrition and some sociodemographic factors. Significance level was set at $5 \%$.

\section{Results \\ Baseline characteristics}

A total of 1213 children less than 15 years were referred to NAUTH Paediatric ART unit during the period under review. However, 99 (8.2\%) children were excluded from the final analysis because they were never successfully engaged in care.

Final analysis for attrition or retention in care was done among 1114 HIV-positive children who were enrolled and followed-up in the Paediatric ART Programme of NAUTH, Nnewi. Some of their baseline characteristics are shown in Table 1. The male: female ratio was approximately 1:1. The age at enrolment ranged from one month to 14 years 11 months with a median and inter-quartile range (IQR) of 4.3 and 6.9 years, respectively. About a third (38.0\%) of them belonged to age group 1 to $<5$ years at enrolment. Majority (71.4\%) did not reside within 15 $\mathrm{km}$ radius of the hospital and had one or both parent (64.5\%) as caregiver. Year 2006 had the highest number of enrolments (13.6\%). Approximately two-thirds (63.2\%) of them had advanced HIV disease (WHO stage 3 or 4 ) at enrolment.

\section{Outcomes}

As shown in Table 2, the rate of loss to follow-up and death were 41.0 and $8.4 \%$ respectively giving a total attrition rate of $49.4 \%$. Loss to follow-up accounted for majority $(83.1 \%)$ of attrition.

The final outcome of majority $(73.7 \%)$ of children who were lost to follow-up could not be ascertained because phone contact was not provided in 56.7\% (191/337) of them or the available phone contact could not be reached (either switched off or belonged to a stranger) in $43.3 \%(146 / 337)$ of them.

As shown in Fig. 1, the commonest reason cited for loss to follow-up among 93 out of 120 caregivers who were successfully contacted was financial constraints (including inability to meet up with cost of transportation and ancillary investigations). Other common reasons were loss of caregiver, claim to divine healing, family disharmony and child custody issues, and relocation of the family. Five children were relocated to another part of the country to serve as domestic helps to other families 
Table 1 Baseline characteristics of children enrolled into NAUTH Nnewi paediatric ART programme between 2003 and 2019

\begin{tabular}{|c|c|}
\hline Characteristic $(n=1114)$ & Frequency (\%) \\
\hline \multicolumn{2}{|l|}{$\overline{\text { Sex }}$} \\
\hline Male & $547(49.1)$ \\
\hline Female & $567(50.9)$ \\
\hline \multicolumn{2}{|l|}{ Age at enrolment } \\
\hline$<$ I year & $183(16.4)$ \\
\hline 1 to $<5$ years & $423(38.0)$ \\
\hline 5 to $<10$ years & 307 (27.6) \\
\hline 10 to $<15$ years & $201(18.0)$ \\
\hline \multicolumn{2}{|l|}{ Clinical stage at enrolment } \\
\hline WHO Stage I or II & $397(35.7)$ \\
\hline WHO stage III or IV & $704(63.2)$ \\
\hline Not available & $13(1.2)$ \\
\hline \multicolumn{2}{|l|}{ Place of residence } \\
\hline Same state $\leq 15 \mathrm{~km}$ from site & $318(28.5)$ \\
\hline Same state $>15 \mathrm{~km}$ from site & $664(59.6)$ \\
\hline Other states & $132(11.8)$ \\
\hline \multicolumn{2}{|l|}{ Caregiver } \\
\hline Parent(s) & $718(64.5)$ \\
\hline Elder sibling & $201(18.0)$ \\
\hline Extended family member & $13(1.2)$ \\
\hline Family friend & $23(2.1)$ \\
\hline Institutional home & $9(0.8)$ \\
\hline Not available & $150(13.5)$ \\
\hline \multicolumn{2}{|l|}{ Year of enrolment } \\
\hline $2003-2005$ & $142(12.7)$ \\
\hline $2006-2008$ & $394(35.4)$ \\
\hline 2009-2011 & $317(28.5)$ \\
\hline 2012-2014 & $137(12.3)$ \\
\hline 2015-2017 & $76(6.8)$ \\
\hline 2018-2019 & $48(4.3)$ \\
\hline
\end{tabular}

who were unaware of their HIV status. Twenty-eight (23.3\%) of them did not proffer any reason for being lost to follow-up.

\section{Trend in attrition}

Figure 2 shows an increase in the retention rate from 14.3 to $81.5 \%$ among those enrolled in 2003 and 2019, respectively. As shown in Table 3 , the overall attrition rate decreased from 85.7 to $18.5 \%$ among children enrolled in 2003 and 2019, respectively. However, the decrease was not steady and fluctuated over the years. Attrition rate was higher than 50\% among those enrolled between years 2003 to 2011, (apart from 2005, 2006 and 2007). A decrease below 50\% occurred from 2012 to 2019 (apart from 2017). The 6-, 12-, 24- and 36-months
Table 2 Outcomes of children enrolled into NAUTH Nnewi Paediatric ART Programme

\begin{tabular}{|c|c|}
\hline Characteristics & Frequency (\%) \\
\hline \multicolumn{2}{|l|}{ Outcome $(n=1114)$} \\
\hline In care & $226(20.3)$ \\
\hline Transitioned to adult ART programme & $223(20.0)$ \\
\hline Transferred out to other paediatric ART sites & $115(10.3)_{-}$ \\
\hline LTFU & $457(41.0)$ \\
\hline Dead & $93(8.4)$ \\
\hline \multicolumn{2}{|l|}{ Attrition rate $(n=1114)$} \\
\hline In care, transitioned or transferred out & $564(50.6)$ \\
\hline LTFU or dead & $550(49.4)$ \\
\hline \multicolumn{2}{|l|}{ Tracking outcomes of children LTFU $(n=457)$} \\
\hline Self-referral to other ART sites & $31(6.8)$ \\
\hline Alive and not in care & $46(10.1)$ \\
\hline Dead while LTFU & $43(9.4)$ \\
\hline Could not be reached & $337(73.7)$ \\
\hline \multicolumn{2}{|l|}{ Duration of care $(n=1114)$} \\
\hline$<1$ year & $336(30.1)$ \\
\hline 1 to $<5$ years & $323(29.0)$ \\
\hline 5 to $<10$ years & $287(25.8)$ \\
\hline 10 to $<15$ years & $164(14.7)$ \\
\hline$>=15$ years & $4(0.4)$ \\
\hline
\end{tabular}

ART anti-retroviral treatment, LTFU lost to follow-up

attrition rates fluctuated over the years. The 6 months attrition was highest among children enrolled in 2017 (45.5\%), 2003 (42.9\%), 2011 (33.0\%) and 2013 (29.2\%). Similar trend was also noted in the 12-, 24- and 36months attrition rates. Overall, the 6-, 12-, 24- and 36months attrition rates were 20.4, 27.7, 34.3 and $37.3 \%$, respectively as shown in Table 3.

\section{Characteristics of children who were dead, lost to follow- up or retained in care}

As shown in Table 4, advanced disease (WHO stage 3 or 4) accounted for 58.2, 66.4 and $87.8 \%$ of children who were retained in care, lost to follow-up or died, respectively. More than half of children who were lost to follow-up (56.4\%) or died (59.2\%) did so within first year of care. Likewise, among those initiated on ARV, more than half of those who were lost to follow-up (55.8\%) or died $(55.7 \%)$ did so within first year of commencement on ARVs.

A higher proportion of those who were lost to followup or died were aged 1 to 5 years at enrolment or last hospital visit. The highest number of loss to follow-up occurred between 2009 and 2011 (10.1\%). On the other hand, the highest number of deaths occurred in 2011 (20.4\%) and 2012(18.3\%). Majority of the children who died were commenced on ARVs (75.3\%) while more 


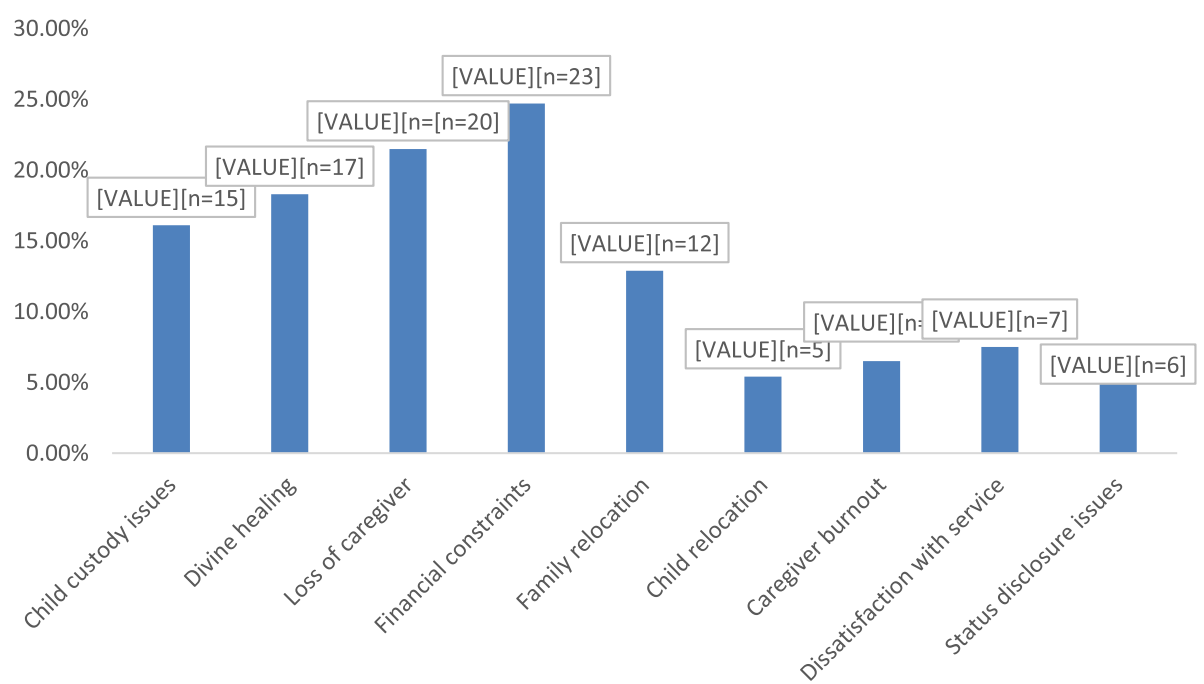

Fig. 1 Reasons for LTFU ( $n=93$, multiple responses)

than half $(56.5 \%)$ of those who were lost to follow-up were on ARVs.

The duration of care, age at enrolment or last hospital visit and interval between ARV initiation and last hospital visit were comparable between children who died or were lost to follow-up. Children who were retained in care had a longer duration of care, and interval between ARV initiation and last hospital visit. A higher proportion of children retained in care belonged to an older age at enrolment. As shown in Fig. 3, retention of children who had WHO stage 4 disease at enrolment as well as those who were not initiated on ARV rapidly decreased within the first year of care.

\section{Results of bivariate and multivariate analysis}

As shown in Table 5, the overall incidence in attrition/ 1000 person years was 108. Children who had advanced disease at enrolment, were not initiated on ARV or less than one year of age at enrolment had a higher incidence in attrition/1000PY. Likewise, those who lived outside Anambra state, whose primary caregiver was a non-family member, and in descending order, those who enrolled in 2018-2019, 2009-2011 and 2015-2017 had higher incidence of attrition/1000 person years. Time to attrition was significantly lower among those who had advanced disease at enrolment or were not commenced on ARV, as well as children enrolled between 2015 and 2017 or 2009-2014. Age less than one year at

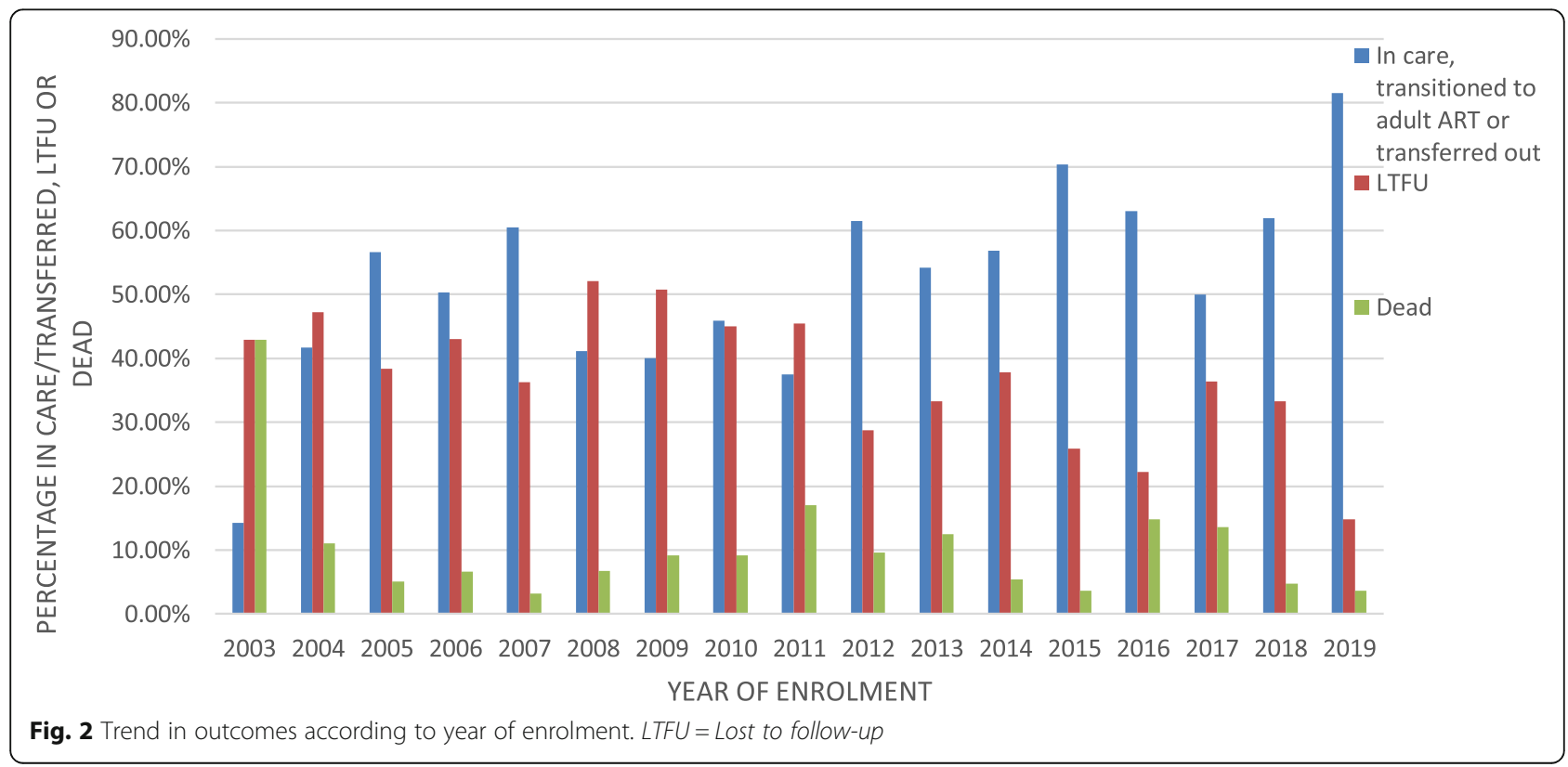


Table 3 Trend in attrition rates according to year of enrolment

\begin{tabular}{|c|c|c|c|c|c|}
\hline \multirow{2}{*}{$\begin{array}{l}\text { Enrolment } \\
\text { Year (n) }\end{array}$} & \multicolumn{5}{|c|}{ Attrition rates according to year of enrolment } \\
\hline & Six months & One year & Two years & Three years & Up to Dec. 2019 \\
\hline $2003(7)$ & $3(42.9)$ & $4(57.1)$ & $5(71.4)$ & $5(71.4)$ & $6(85.7)$ \\
\hline $2004(35)$ & $8(22.2)$ & 11(30.6) & 14(38.9) & $15(41.7)$ & $21(58.3)$ \\
\hline $2005(99)$ & 13(13.1) & 18(18.2) & $21(21.2)$ & 23(23.2) & $43(43.4)$ \\
\hline $2006(151)$ & $34(22.5)$ & $42(27.8)$ & $49(32.5)$ & $53(35.1)$ & $75(49.7)$ \\
\hline $2007(124)$ & $22(17.7)$ & $28(22.6)$ & $35(28.2)$ & 38(30.6) & $49(39.5)$ \\
\hline 2008 (119) & 20(16.8) & $31(26.1)$ & $34(28.6)$ & $38(31.9)$ & $70(58.8)$ \\
\hline $2009(120)$ & $27(22.5)$ & $36(30.0)$ & $46(38.3)$ & $53(44.2)$ & $72(60.0)$ \\
\hline 2010 (109) & $18(16.5)$ & $29(26.6)$ & $42(38.5)$ & $46(42.2)$ & $59(54.1)$ \\
\hline 2011 (88) & 29(33.0) & $38(43.2)$ & $46(52.3)$ & $48(54.5)$ & $55(62.5)$ \\
\hline 2012 (52) & $8(15.4)$ & $12(23.1)$ & $13(25.0)$ & $17(32.7)$ & $20(38.5)$ \\
\hline 2013 (48) & $14(29.2)$ & $16(33.3)$ & 18(37.5) & 19(39.6) & $22(45.8)$ \\
\hline 2014 (36) & $6(16.2)$ & $10(27.0)$ & 14(37.8) & $15(40.5)$ & $16(43.2)$ \\
\hline 2015 (26) & $4(14.8)$ & $5(18.5)$ & $8(29.6)$ & $8(29.6)$ & $8(29.6)$ \\
\hline 2016 (26) & $4(14.8)$ & $7(25.9)$ & $9(33.3)$ & $10(37.0)$ & $10(37.0)$ \\
\hline 2017 (21) & $10(45.5)$ & $10(45.5)$ & $11(50.0)$ & $11(50.0)$ & $11(50.0)$ \\
\hline 2018 (20) & 4(19.0) & $6(28.6)$ & 7(38.9) & - & $8(38.1)$ \\
\hline 2019 (26) & $3(11.1)$ & $3(16.7)$ & - & - & $5(18.5)$ \\
\hline Total (1114) & $227(20.4)$ & $306(27.7)$ & $372(34.3)$ & $399(37.5)$ & $550(49.4)$ \\
\hline
\end{tabular}

enrolment, having non-family member as primary caregiver and living outside Anambra state had the least time to attrition but these did not achieve statistical significance.

In bivariate analysis, WHO clinical stage and age at enrolment, not being commenced on ARV, primary caregiver, and period of enrolment were associated with attrition. Apart from primary caregiver, these factors remained significant in multivariate analysis. Use of ARVs reduced the risk of attrition by $88 \%$. Enrolment age less than one year, and one to five years had 105 and $41 \%$ higher risk of attrition, respectively, compared to age 10 years or above. Living within $15 \mathrm{~km}$ to the hospital reduced attrition by $19 \%$ compared to those who lived outside Anambra State, although this was not statistically significant. Having elder sibling or parent(s) as primary care giver reduced attrition by 81 and 19\%, respectively, compared to a non-family member although this factor did not attain statistical significance in multivariate analysis.

\section{Discussion}

Our findings portray a high attrition rate among children living with HIV. Among children who were referred to the unit, $8.2 \%$ did not complete the enrolment process and return for the next visit. Among those who were successfully linked to care, the overall attrition rate was $49.4 \%$ with incidence of 108/1000 person years while the 6-, 12-, 24-, and 36-months attrition rates were 20.4, 27.7, 34.3 and $37.5 \%$, respectively. These findings are comparable to reports from similar African studies [12-19].

The pre-engagement attrition highlights the success of linkage to care. Successful linkage to care requires navigation through post-test counselling, transfer to clinic, enrolment protocols, initial clinical and laboratory evaluation, ART initiation and first follow-up visit. Some of these services may be hindered by health system related factors such as user fees and long waiting time. In addition, as revealed by our findings, many children present with advanced HIV disease and may die before the first follow-up visit. Children are completely dependent on adult caregivers to access care. Therefore, caregiver issues such as status denial, fear of stigmatization, ill health, death and financial constraints could hinder successful linkage to care. Current efforts to address the gap of successful linkage include rapid ART initiation and case management approach [1-23]. The case management approach ensures that a newly diagnosed HIV positive individual is successfully linked to coordinated health and social services to achieve desired outcomes [24]. This approach is patient centered, an ongoing rather than a one-off process, and responds to the peculiar needs of the client [24]. Although these interventions have been demonstrated to improve successful linkage to care, their implementation should be intensified and monitored to achieve desired results. 
Table 4 Characteristics of children retained in care, dead or LTFU

\begin{tabular}{|c|c|c|c|c|}
\hline Characteristics & In care or referred & LTFU & Dead & $p$-value \\
\hline \multicolumn{5}{|l|}{ Clinical stage at enrolment $(n=1101)$} \\
\hline WHO stage 1 & $75(13.3)$ & $44(9.9)$ & $3(3.2)$ & \\
\hline WHO stage 2 & $161(28.5)$ & $105(23.6)$ & $9(9.7)$ & \\
\hline WHO stage 3 & 297(52.7) & $247(55.6)$ & $53(57.0)$ & \\
\hline WHO stage 4 & $31(5.5)$ & $48(10.4)$ & 28(30.1) & \\
\hline Duration of care & $(n=564)$ & $(n=457)$ & $(n=93)$ & \\
\hline$<6$ months & $9(1.6)$ & 192(42.0) & $42(45.2)$ & \\
\hline 6 months to $<12$ months & $14(2.5)$ & $66(14.4)$ & 13(14.0) & \\
\hline 1 to $<5$ years & $165(29.3)$ & 137(30.0) & $21(22.6)$ & \\
\hline 5 to $<10$ years & $227(40.2)$ & $48(10.5)$ & $12(12.9)$ & \\
\hline 10 to $<15$ years & $145(25.7)$ & $14(3.1)$ & $5(5.4)$ & \\
\hline$\geq 15$ years & $4(0.7)$ & $0(0.0)$ & $0(0.0)$ & \\
\hline Median care duration (IQR) in years & $6.9(6.3)$ & $0.7(2.8)$ & $0.6(3.3)$ & $<0.001^{*}$ \\
\hline Age at enrolment (years) & $(n=564)$ & $(n=457)$ & $(n=93)$ & \\
\hline$<1$ year & $79(14.0)$ & $84(18.4)$ & $20(21.5)$ & \\
\hline 1 to $<5$ years & 198(35.1) & 189(41.4) & $36(38.7)$ & \\
\hline 5 to $<10$ years & 163(28.9) & $121(26.5)$ & $23(24.7)$ & \\
\hline 10 to $<15$ years & $124(22.0)$ & 63(13.8) & 14(15.1) & \\
\hline Median enrolment age (IQR) in years & $5.1(7.7)$ & $3.8(6.0)$ & $2.6(6.3)$ & $<0.001^{*}$ \\
\hline Age at last visit (years) & $(n=564)$ & $(n=457)$ & $(n=93)$ & \\
\hline$<1$ year & $2(0.4)$ & $43(9.4)$ & $10(10.8)$ & \\
\hline 1 to $<5$ years & $33(5.9)$ & 152(33.3) & $30(32.3)$ & \\
\hline $5<10$ years & 104(18.4) & 139(30.4) & $25(26.9)$ & \\
\hline 10 to $<15$ years & 201(35.6) & 105(23.0) & $26(28.0)$ & \\
\hline$>=15$ years & 224(39.7) & 18(3.9) & $2(2.2)$ & \\
\hline Median last visit age (IQR) in years & $14.1(5.4)$ & $6.0(7.7)$ & $6.3(9.4)$ & $<0.001^{*}$ \\
\hline \multicolumn{5}{|l|}{ Use of ARV } \\
\hline Yes & $538(95.4)$ & $258(56.5)$ & $70(75.3)$ & \\
\hline No & $26(4.6)$ & 199(43.5) & $23(24.7)$ & \\
\hline Enrolment and ARV initiation interval (months) & $n=538$ & $n=258$ & & \\
\hline Mean \pm SD & $12.9 \pm 25.84$ & $6.7 \pm 17.45$ & $7.8 \pm 16.51$ & $<0.001^{\dagger}$ \\
\hline ARV initiation and last visit interval (years) & $n=538$ & $n=258$ & $n=70$ & \\
\hline$<1$ year & $40(7.4)$ & 144(55.8) & $39(55.7)$ & \\
\hline 1 to $<5$ years & 197(36.6) & $72(27.9)$ & $20(28.6)$ & \\
\hline 5 to $<10$ years & 199(37.0) & $33(12.8)$ & $7(10.0)$ & \\
\hline 10 years $<15$ years & $102(19.0)$ & $9(3.5)$ & $4(5.7)$ & \\
\hline Median ARV initiation and last visit interval (IQR) & $5.7(6.1)$ & $0.6(3.0)$ & $0.6(2.8)$ & $<0.001^{*}$ \\
\hline
\end{tabular}

LTFU loss to follow-up, IQR interquartile range, $S D$ standard deviation, $A R V$ anti-retrovirals

*Statistically significant Kruskal-Wallis test, ${ }^{+}$Statistically significant one-way ANOVA

The findings of this study are in keeping with previous reports of high attrition rates in West African Paediatric ART Programmes [15, 18, 25]. The West African subregion has been reported to have the poorest retention in care compared to other parts of the world. In addition, a wide disparity exists between attrition rates in developed and developing countries [26, 27]. Urgent innovative interventions are needed to address the high attrition rates in West Africa in order to achieve the 2030 global targets [7]. Reports consistently show that 

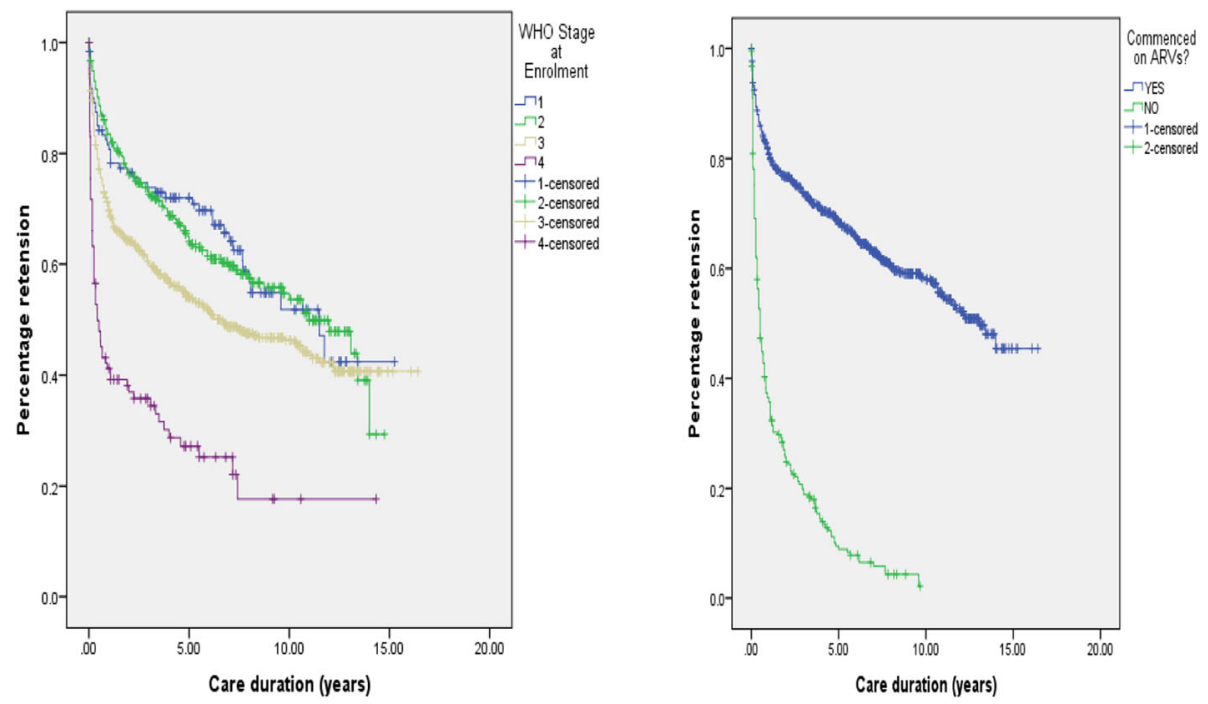

Fig. 3 Kaplan-Meier survival curves according to initial WHO clinical stage or use of ARVs

loss to follow-up constitute majority of attrition among children enrolled in HIV treatment programmes in developing countries [12-19, 27, 28]. However, this should be interpreted with caution because a significant proportion of loss to-follow up may be actual deaths. This hypothesis was supported by the finding that children who were lost to follow-up shared similar characteristics with those who died and this is substantiated by previous report [29]. The fact that majority of children who were lost to follow-up could not be reached on phone was somewhat disappointing. The inability to reach them could be attributed to loss/replacement of sim cards as well as the multiplicity of individual sim card ownership in the country. This challenge buttresses the need for innovative tracking approach that will ensure efficient real-time tracking, quick re-engagement in care and proper documentation of true outcomes [30]. Adequate funds should be earmarked for tracking down to the household and community levels should phone calls fail as experienced in the index study.

The findings from caregivers who were successfully reached provided insight into the outcomes of children who were lost to follow-up. More than a third died while lost to follow-up (35.3\%) or were alive but not in any form of care $(38.7 \%)$, while a quarter $(26.1 \%)$ started accessing care at other sites. This reinforces the need for innovative strategies that can identify enrollees who were previously in care or ART experienced to ensure appropriate documentation and reporting of outcomes. The reasons for being lost to follow-up highlight the challenges faced by HIV-infected children and their caregivers. This is buttressed by a Zimbabwean report [31]. Expectedly, most of the issues were caregiver related.
Our findings agree with a report which showed that financial constraints pose the commonest barrier to continued engagement in care in developing countries [25]. Although anti-retroviral drugs are free, families may not meet up with the cost of certain services including ancillary laboratory investigations, folder/card fees, treatment of co-morbidities, as well as frequent transportation to and from hospitals. More so, this may be aggravated by the indirect cost of the lifelong sickness on the family. In order to address these challenges, the World Health Organization adopted a public health approach in HIV programmes. This includes task sharing, decentralization and integration of HIV services with other health services and differentiated service delivery (DSD). Task shifting and decentralization of services to peripheral health centers are believed to increase the number of healthcare workers and facilities providing ART services, thereby, bringing services closer to clients' doorsteps. However, accessing care from a nearby facility may not be acceptable to caregivers due to fear of stigmatization. Therefore, efforts to minimize stigmatization should be intensified to ensure that children are treated in facilities as close as possible to their homes in order to reduce transportation cost.

The differentiated service delivery is a client centered approach that focuses on the preferences, needs and values of clients while reducing unnecessary burden on the healthcare facilities. However, children were not prioritized in the initial scale up of DSD. This was attributed to the fact that children often have age-related clinical issues that may require specialist care or more intensive follow up. For instance, rapid growth during the first two years of life necessitates frequent weight 
Table 5 Result of bivariate and multivariate analysis of factors associated with attrition

\begin{tabular}{|c|c|c|c|c|c|c|c|c|c|c|}
\hline Variable & Total & PT Years & $\begin{array}{l}\text { Attrition } \\
(\%)\end{array}$ & $P$-value & $\begin{array}{l}\text { Estimated time } \\
\text { to event (years) }\end{array}$ & $p$-value & $\begin{array}{l}\text { Attrition } \\
\text { /1000PY }\end{array}$ & B & HR & $P$-value \\
\hline Total & 1114 & 5109.7 & $550(49.4)$ & & 7.3 & & 108 & & & \\
\hline Clinical stage & & & & & & & & & & $<0.001^{c}$ \\
\hline WHO stage 1 & 122 & 646.1 & $47(38.5)$ & & 11.5 & $<0.001$ & 73 & -1.81 & $0.16(0.11-0.25)$ & $<0.001$ \\
\hline WHO stage 2 & 275 & 1488.2 & $114(41.5)$ & $<0.001^{a}$ & 11.0 & & 77 & -1.62 & $0.20(0.14-0.28)$ & $<0.001$ \\
\hline WHO stage 3 & 597 & 2767.0 & $300(50.3)$ & & 6.7 & & 108 & -0.96 & $0.39(0.29-0.52)$ & $<0.001$ \\
\hline WHO stage 4 & 107 & 203.8 & $76(71.0)$ & & 0.4 & & 373 & - & Reference & - \\
\hline \multicolumn{11}{|l|}{ Use of ARVs } \\
\hline Yes & 866 & 4762.9 & $328(37.9)$ & $<0.001^{a}$ & 13.1 & $<0.001^{b}$ & 69 & -2.13 & $0.12(0.09-0.15)$ & $<0.001^{c}$ \\
\hline No & 248 & 346.8 & $222(89.5)$ & & 0.5 & & 640 & - & Reference & \\
\hline Sex & & & & & & & & & & 0.873 \\
\hline Male & 547 & 2603.9 & $266(48.6)$ & 0.626 & 7.4 & 0.375 & 102 & 5.09 & 161.99 & 0.859 \\
\hline Female & 567 & 2505.8 & $284(50.1)$ & & 6.7 & & 113 & 5.04 & 154.27 & 0.860 \\
\hline Enrolment Age (years) & & & & & & & & & & $0.001^{c}$ \\
\hline$<1$ & 183 & 874.8 & 104(56.8) & & 5.3 & & 568 & 0.72 & $2.05(1.40-3.00)$ & $<0.001^{c}$ \\
\hline 1 to $<5$ & 423 & 2205.2 & $225(53.2)$ & $0.001^{\mathrm{a}}$ & 6.9 & 0.121 & 102 & 0.35 & $1.41(1.02-1.96)$ & 0.037 \\
\hline $5-<10$ & 307 & 1371.9 & 144(46.9) & & 6.8 & & 105 & 0.16 & $1.17(0.83-1.66)$ & 0.362 \\
\hline 10 to $<15$ & 201 & 657.8 & 77(38.3) & & 7.3 & & 117 & - & Reference & - \\
\hline Caregiver & & & & & & & & & & 0.142 \\
\hline Parent(s) & 718 & 3721.1 & $307(42.8)$ & & 11.5 & & 83 & -0.21 & $0.81(0.49-1.34)$ & 0.417 \\
\hline Sibling & 13 & 46.8 & $1(7.7)$ & & - & & 21 & -1.65 & $0.19(0.03-1.45)$ & 0.109 \\
\hline Extended family member & 201 & 910.6 & $95(47.3)$ & $0.026^{\mathrm{a}}$ & 7.8 & 0.073 & 104 & -0.01 & $0.99(0.59-1.68)$ & 0.981 \\
\hline Others & 32 & 138.5 & 17(53.1) & & 5.1 & & 123 & - & Reference & - \\
\hline Place of residence & & & & & & & & & & 0.577 \\
\hline Same state $\leq 15 \mathrm{~km}$ radius & 162 & 810.9 & $79(48.8)$ & 0.058 & 8.1 & 0.065 & 97 & -0.21 & $0.81(0.49-1.34)$ & 0.299 \\
\hline Same state $>15 \mathrm{~km}$ from site & 820 & 3839.7 & $400(48.8)$ & & 7.5 & & 104 & -0.11 & $0.90(0.65-1.24)$ & 0.515 \\
\hline Other states & 132 & 459.1 & $71(53.8)$ & & 3.9 & & 155 & - & Reference & - \\
\hline Period of enrolment & & & & & & & & & & $<0.001^{c}$ \\
\hline 2003-2005 & 142 & 889.2 & $70(49.3)$ & & 9.2 & & 79 & -0.25 & $0.78(0.38-1.63)$ & 0.512 \\
\hline 2006-2008 & 394 & 2300.7 & 194(49.2) & & 8.3 & $0.001^{b}$ & 84 & -0.67 & $0.51(0.25-1.04)$ & 0.063 \\
\hline 2009-2011 & 317 & 1171.7 & 186(58.7) & $<0.001^{\mathrm{a}}$ & 5.5 & & 159 & -0.19 & $0.83(0.41-1.67)$ & 0.595 \\
\hline 2012-2014 & 137 & 499.8 & $58(42.3)$ & & 5.2 & & 116 & -0.05 & $0.95(0.46-1.97)$ & 0.897 \\
\hline 2015-2017 & 76 & 191.4 & 29(38.2) & & 3.5 & & 152 & -0.00 & $1.00(0.46-2.20)$ & 0.997 \\
\hline 2018-2019 & 48 & 57.0 & $13(27.1)$ & & 2.0 & & 228 & - & Reference & - \\
\hline
\end{tabular}

${ }^{a}$ Statistically significant chi-square test ${ }^{b}$ Statistically significant Log rank (Kaplan Meier)

${ }^{c}$ Statistically significant Cox regression $B=$ regression coefficient $H R=$ Hazard ratio

monitoring and weight-based dosage adjustment. However, children above 2 years can benefit from multi month scripting, and family-centered approaches including same-day appointments, duration of ART refills or allowing family member to collect ART refills. DSD has been documented to optimize quality of care, efficiency, client satisfaction and continued engagement in care. Therefore, the application of some DSD models should be explored in paediatric ART programmes. In addition, programmes should adopt child-centered interventions that can step in when HIV-infected children experience complex problems, which have the potential to terminate their treatment. Such interventions may include legal support especially for children in unstable homes, enforcement of legislation against child labour, and economic empowerment for the child's family. Efforts should be made to ensure that HIV-positive children remain on treatment irrespective of caregiver's religious belief, death, relocation and financial status. Quality adherence counselling and psychosocial support for the 
child and family are vital to the success of paediatric ART programmes.

Unexpectedly, the trend in attrition failed to assume a steady decline despite the reported scale up of case identification, linkage to care and treatment monitoring. This may reflect fluctuation in programme funding and treatment policies $[1,5]$. Reports consistently show an association between delay in initiation on ART or very young age and high risk of attrition [12, 13, 15, 25, 32-35]. This justifies the adoption of the "test and treat" and rapid ART initiation approaches [24]. However, the patients should be closely monitoring during the first 6 months of ART since this period has been consistently reported to account for a significant proportion of attrition $[12,13,15,25-27,32-35]$. The under-fives represent a highly vulnerable population due to rapid disease progression and high risk of death. Hence, this age group should be closely monitored to forestall death or loss to follow-up. Furthermore, programmes should ensure potent age-appropriate regimens and dosages. Our finding that about two-thirds of all children had advanced WHO clinical stage at enrolment agrees with previous African reports [13, 17, 25-31]. This calls for intensified efforts at identifying infected pregnant women and linking them to prevention of MTCT programmes as well as early infant diagnosis.

The association between attrition and having parent(s) as caregiver agrees with previous reports [13, 31]. This may not be unconnected with the fact that the parent(s) may be sick or die eventually, may be in denial of status, or experiencing financial difficulties due to ill health. These may explain the high attrition also recorded in adult ART programmes [36, 37]. Therefore, parents need adequate support to enable them remain alive and healthy, and to continue to take care for their infected children. Surprisingly, only one out of 13 children who had elder sibling as caregiver died and none was lost to follow-up. Programmes can explore the possibility of engaging elder siblings as secondary caregivers or primary caregivers in the event of loss of parent(s), rather than transferring care to other family members or non-family members thereby increasing the risk of attrition.

\section{Conclusion and recommendations}

The Paediatric HIV treatment programme in Nnewi, Nigeria recorded a high rate of attrition which was mostly due to loss to follow-up. Most children lost to follow-up could not be reached on phone. Major reasons for being lost to follow-up were financial constraints, loss of caregiver, claim to divine healing, family disharmony, child custody issues, and relocation of family or child. Predictors of attrition were advanced HIV disease, young age at enrolment, delay in initiating ARVs, primary caregiver, and period of enrolment.
HIV treatment service delivery should be tailored to the needs of the child and his/her family. Efforts should be intensified at early diagnosis, successful linkage to care and effective implementation of the "test and treat" strategy. Innovative child centered approaches and interventions should be adopted to enable the HIV-infected child continue treatment despite challenges which have the potential to truncate treatment. Removal of user fees and re-activation of home-visit as a component of tracking are recommended.

\section{Acknowledgments}

We are grateful to all nurses, doctors and other staff working in the Paediatric Infectious Diseases Unit of NAUTH, Nnewi. We appreciate the assistance of the focal person of the NAUTH HIV-care monitoring and evaluation (M/E) unit during the data abstraction.

\section{Authors' contributions \\ The authors' contributions are as follows. Study conception and design: CUO, EFU. Data collection: CUO, EFU. Analysis: CUO. Interpretation of data: CUO, EFU. Drafting of manuscript: CUO. Critical revision: CUO, EFU. The authors read and approved the final manuscript.}

\section{Funding}

No funding was received for this study.

\section{Availability of data and materials}

The study dataset is available and can be obtained from the corresponding author on reasonable request.

\section{Declarations}

Ethics approval and consent to participate

Ethical clearance for the study was obtained from NAUTH Ethics Committee. All aspects of the study were carried out in accordance with relevant guidelines and regulations/declaration of Helsinki. All caregivers provided informed consent to be called on phone, in the event of loss to follow-up, for the purpose of tracking. All data obtained during the study was kept confidential.

\section{Consent for publication \\ Not applicable.}

\section{Competing interests}

The authors have no competing interests that might be perceived to influence the results and or discussion reported in this paper.

Received: 16 January 2021 Accepted: 19 April 2021

Published online: 03 May 2021

\section{References}

1. UNICEF. Improving HIV service delivery for infants, children and adolescents: a framework for country programming. New York: UNICEF; 2020. Available from: http://www.childrenandaids.org/paediatricservice-delivery-framework

2. UNAIDS. UNAIDS reference DATA 2019. Geneva: UNAIDS; 2019. Available from: https://www.unaids.org/sites/default/files/media_asset/2019-UNAIDSdata_en.pdf

3. ANECCA. Handbook on Paediatric AIDS in Africa by the African Network for the Care of Children Affected by HIV/AIDS. Kampala, ANECCA; 2017. 4th Ed. Available at: www.anecca.org. Accessed 12 Dec 2019.

4. Cardoso CA, Pinto JA, Candiani TM, de Carvalho IR, Linhares RM, Goulart EM. The impact of highly active antiretroviral therapy on the survival of vertically HIV-infected children and adolescents in Belo Horizonte, Brazil. Mem Inst Oswaldo Cruz. 2012;107(4):532-8. https://doi.org/10.1590/S0074-02762012 000400014.

5. PEPFAR. PEPFAR 2020 Country Operational Plan Guidance for all PEPFAR Countries. Available from: https:/www.state.gov/wp-content/uploads/2020/ 01/COP20-Guidance_Final-1-15-2020.pdf. Accessed 5 Oct 2020. 
6. UNAIDS. 90-90-90 an ambitious treatment target to help end the AIDS epidemic. Geneva: UNAIDS; 2014. Available from: https://www.unaids.org/ sites/default/files/media_asset/90-90-90_en.pdf

7. UNAIDS. Understanding fast-track: accelerating actions to end the AIDS epidemic by 2030. Geneva: UNAIDS; 2015. Available from: https://www.una ids.org/sites/default/files/media_asset/201506_JC2743_Understanding_Fa stTrack_en.pdf

8. FMOH. National Guidelines for HIV and AIDS treatment and Care in Adolescents and Adults 2007. Abuja: FMOH; 2007.

9. FMOH. National Guidelines for Paediatric HIV and AIDS treatment and care 2007. Abuja: FMOH; 2007.

10. NASCP/FMOH. Integrated National Guidelines for HIV Prevention, Treatment and Care 2014. Abuja: FMOH; 2014.

11. NASCP/FMOH. National Guidelines for HIV Prevention Treatment and Care 2016. Abuja: FMOH; 2016.

12. Massavon $W$, Lundin $R$, Costenaro $P$, Penazzato $M$, Namisi $P$, Ingabire $R$, et al. Attrition and loss to follow-up Among Children and Adolescents in a community Home-Based Care HIV Programme in Uganda. Pediat Therapeut. 2013;3:5.

13. Massavon W, Barlow-Mosha L, Mugenyi L, McFarland W, Gray G, Lundin R. Factors determining survival and retention among HIV-infected children and adolescents in a community home-based care and a facility-based family-centered approach in Kampala. Uganda: A Cohort Study. ISRN AIDS; 2014. p. 1-13.

14. $\mathrm{FMOH}$. Report on the assessment of paediatric HIV in Nigeria. Abuja: $\mathrm{FMOH} ; 2014$.

15. Abuogi LL, Smith C, McFarland EJ. Retention of HIV-infected children in the first 12 months of anti-retroviral therapy and predictors of attrition in resource limited settings: systematic review. PLoS One. 2016;11(6):e0156506. https://doi.org/10.1371/journal.pone.0156506.

16. McNairy ML, Lamb MR, Carter RJ, Fayorsey R, Tene G, Mutabazi V, et al. For identifying optimal models of HIV care and treatment in sub-Saharan Africa consortium. Retention of HIV-infected children on antiretroviral treatment in HIV care and treatment programs in Kenya, Mozambique, Rwanda, and Tanzania. J Acquir Immune Defic Syndr. 2013;62(3):e70-81. https://doi.org/1 0.1097/QAl.0b013e318278bcb0.

17. Sengayi M, Dwane N, Marinda E, Sipambo N, Fairlie L, Moultrie H. Predictors of loss to follow-up among children in the first and second years of antiretroviral treatment in Johannesburg, South Africa. Glob Health Action. 2013;6(1):19248. https://doi.org/10.3402/gha.v6i0.19248.

18. Carluccia JG, Liu Y, Clousea K, Vermund SH. Attrition of HIV-positive children from HIV services in low and middle-income countries. AIDS. 2019;33(15): 2375-86. https://doi.org/10.1097/QAD.0000000000002366.

19. Biru M, Hallström I, Lundqvist $P$, Jerene D. Rates and predictors of attrition among children on antiretroviral therapy in Ethiopia: a prospective cohort study. PLoS One. 2018;13(2):e0189777. https://doi. org/10.1371/journal.pone.0189777.

20. $\mathrm{FMOH}$. Federal tertiary facilities: HIV/AIDS sustainability roadmap for HIV response (2016-2018). Abuja: FMOH; 2016.

21. Herce ME, Chi BH, Liao RC, Hoffmann CJ. Re-thinking linkage to care in the era of universal test and treat: insights from implementation and behavioral science for achieving the second 90. AIDS Behav. 2019;23(Suppl 2):120-8. https://doi.org/10.1007/s10461-019-02541-5.

22. Bunda BA, Bassett IV. Reaching the second 90: the strategies for linkage to care and antiretroviral therapy initiation. Curr Opin HIV AIDS. 2019;14(6):494502. https://doi.org/10.1097/COH.0000000000000579.

23. World Health Organization. Consolidated guidelines on the use of antiretroviral drugs for treating and preventing HIV infection: recommendations for a public health approach. Second Edition. Geneva: World Health Organization; 2016.

24. Nai-Ying K, Hsiao-Ying L, Yi-Yin L, Pi Y-H, Wen-Chien K. Case management interventions for HIV-infected individuals. Curr HIV/AIDS Rep. 2013;10(4):390-7.

25. Leroy A, Malateste K, Rabie H, Lumbiganon P, Ayaya S, Dicko F, et al. Outcomes of antiretroviral therapy in children in Asia and Africa: a comparative analysis of the leDEA pediatric multiregional collaboration. J Acquir Immune Defic Syndr. 2013;62(2):208-19. https://doi.org/10.1097/QAI. Ob013e31827b70bf.

26. Judd A, Doerholt K, Tookey PA, Sharland M, Riordan A, Menson E, et al. Morbidity, mortality, and response to treatment by children in the United Kingdom and Ireland with perinatally acquired HIV infection during 1996-
2006: planning for teenage and adult care. Clin Infect Dis. 2007:45(7):918-24 https://doi.org/10.1086/521167

27. Peacock-Villada E, Richardson BA, John-Stewart GC. Post-HAART outcomes in pediatric populations: comparison of resource-limited and developed countries. Pediatrics. 2011;127(2):e423-41. https://doi.org/10.1542/peds.2 009-2701.

28. Minn AC, Kyaw NT, Mon OM, Htun T, Oo MM, Moe J, et al. Attrition among HIV positive children enrolled under integrated HIV care programme in Myanmar: 12 years cohort analysis. Glob Health Action. 2018;11(1):1510593. https://doi.org/10.1080/16549716.2018.1510593.

29. Izudi J, Mugenyi J, Mugabekazi M, Muwanika B, Spector VT, Katawera A, et al. Retention of HIV-positive adolescents in care: a quality improvement intervention in mid-Western Uganda. Biomed Res Int. 2018;2018:1-8. https:// doi.org/10.1155/2018/1524016.

30. Grimwood A, Fatti G, Mothibi E, Malahlela M, Shea J, Eley B. Community adherence support improves programme retention in children on antiretroviral treatment: a multicentre cohort study in South Africa. J Int AIDS Soc. 2012;15:17381.

31. Busza J, Dauya E, Bandason T, Mujuru H, Ferrand RA. "I don't want financial support but verbal support." How do caregivers manage children's access to and retention in HIV care in urban Zimbabwe? J Int AIDS Soc. 2014;17(1): 18839. https://doi.org/10.7448/IAS.17.1.18839.

32. Raguenaud M, Isaakidis P, Zachariah R, Vantha T, Soeung S, Akao K, et al. Excellent outcomes among HIV+ children on ART, but unacceptably high pre-ART mortality and losses to follow-up: a cohort study from Cambodia. BMC Pediatr. 2009;9(1):54. https://doi.org/10.1186/1471-2431-9-54.

33. Ditekemena J, Luhata C, Bonane W, Kiumbu M, Tshefu A, Colebunders R, et al. Antiretroviral treatment program retention among HIV-infected children in the Democratic Republic of Congo. PLoS One. 2014;9(12): e113877. https://doi.org/10.1371/journal.pone.0113877.

34. Oo MM, Gupta V, Aung TK, Kyaw NT, Oo HN, Kumar AM. Alarming attrition rates among HIV-infected individuals in pre-antiretroviral therapy care in Myanmar, 2011-2014. Glob Health Action. 2016;9:31280.

35. Agolory SG, Auld AF, Odafe S, Shiraishi RW, Dokubo EK, Swaminathan M, et al. High rates of loss to follow-up during the first year of pre-antiretroviral therapy for HIV patients at sites providing pre-ART care in Nigeria, 20042012. PLoS One. 2017;12(9):e0183823. https://doi.org/10.1371/journal.pone. 0183823.

36. Stafford KA, Odafe SF, Lo J, Ibrahim R, Ehoche A, Niyang M, et al. Evaluation of the clinical outcomes of the test and treat strategy to implement treat all in Nigeria: results from the Nigeria multi-center ART study. PLoS One. 2019; 14(7):e0218555. https://doi.org/10.1371/journal.pone.0218555.

37. Umeokonkwo CD, Onoka CA, Agu PA, Ossai EN, Balogun MS, Ogbonnaya LU. Retention in care and adherence to HIV and AIDS treatment in Anambra state Nigeria. BMC Infect Dis. 2019;19(1):654. https://doi.org/10.11 86/s12879-019-4293-8.

\section{Publisher's Note}

Springer Nature remains neutral with regard to jurisdictional claims in published maps and institutional affiliations.

Ready to submit your research? Choose BMC and benefit from:

- fast, convenient online submission

- thorough peer review by experienced researchers in your field

- rapid publication on acceptance

- support for research data, including large and complex data types

- gold Open Access which fosters wider collaboration and increased citations

- maximum visibility for your research: over $100 \mathrm{M}$ website views per year

At $\mathrm{BMC}$, research is always in progress.

Learn more biomedcentral.com/submissions 